\title{
Crisaborole Ointment Improves Quality of Life of Patients with Mild to Moderate Atopic Dermatitis and Their Families
}

Eric L. Simpson · Amy S. Paller · Mark Boguniewicz • Lawrence F. Eichenfield •

Steven R. Feldman · Jonathan I. Silverberg · Sarah L. Chamlin •

Lee T. Zane

Received: June 4, 2018 / Published online: October 22, 2018

(C) The Author(s) 2018

\section{ABSTRACT}

Introduction: The impact of crisaborole ointment, a nonsteroidal phosphodiesterase 4 inhibitor for the treatment of mild to moderate atopic dermatitis (AD), on quality of life (QoL) was assessed in two identically designed phase 3 studies

Enhanced digital features To view enhanced digital features for this article go to https://doi.org/10.6084/ m9.figshare.7094279.

E. L. Simpson ( $₫)$

Department of Dermatology, Oregon Health and Science University, Portland, OR, USA

e-mail: simpsone@ohsu.edu

\section{A. S. Paller}

Northwestern University Feinberg School of

Medicine, Chicago, IL, USA

M. Boguniewicz

Division of Allergy-Immunology, Department of

Pediatrics, National Jewish Health, Denver, CO, USA

\section{Boguniewicz}

Department of Pediatrics, University of Colorado

School of Medicine, Denver, CO, USA

L. F. Eichenfield

Division of Pediatric and Adolescent Dermatology, Rady Children's Hospital-San Diego, San Diego, CA, USA

L. F. Eichenfield

Department of Dermatology, University of

California, San Diego, CA, USA
(AD-301: NCT02118766; AD-302: NCT02118792, both at http://www.clinicaltrials.gov).

Methods: In both studies, patients aged $\geq 2$ years with mild to moderate $\mathrm{AD}$ per the Investigator's Static Global Assessment were randomly assigned 2:1 to receive crisaborole or vehicle twice daily for 28 days. QoL was assessed using the Children's Dermatology Life Quality Index (CDLQI) (2-15 years), the Dermatology Life Quality Index (DLQI) ( $\geq 16$ years), and the Dermatitis Family Impact Questionnaire (DFI) (parents/caregivers/family of patients aged

\section{F. Eichenfield}

Department of Pediatrics, University of California, San Diego, CA, USA

\section{S. R. Feldman}

Department of Dermatology, Wake Forest

University School of Medicine, Winston-Salem, NC, USA

\section{J. I. Silverberg}

Department of Dermatology, Northwestern University Feinberg School of Medicine, Chicago, IL, USA

\section{S. L. Chamlin}

Department of Pediatrics, Ann and Robert H. Lurie Children's Hospital of Chicago, Northwestern

University Feinberg School of Medicine, Chicago, IL, USA

L. T. Zane

Anacor Pharmaceuticals, Inc., a wholly owned subsidiary of Pfizer Inc., New York, NY, USA 
2-17 years). Established QoL score severity bands provided clinical context.

Results: Greater mean improvement in QoL was observed in crisaborole-treated patients than in vehicle-treated patients at day 29 [mean change from baseline $(\Delta \mathrm{BL}), \mathrm{CDLQI}:-4.6$ vs. $-3.0 ; \quad P<0.001 ;$ DLQI: -5.2 vs. -3.5 ; $P=0.015]$. At baseline, more than half the patients had a "moderate effect" or higher of AD on QoL. At day 29, there was a trend toward more crisaborole- than vehicle-treated patients having "small effect" to "no effect", The QoL of parents/caregivers/family improved more for crisaborole-treated than for vehicle-treated patients ( $\triangle \mathrm{BL}$, DFI: -3.7 vs. $-2.7 ; P=0.003)$.

Conclusion: Crisaborole treatment results in clinically meaningful improvement in QoL for patients and their parents/caregivers/families.

Trial Registration: AD-301: http://www.clini caltrials.gov, NCT02118766; AD-302: http://www. clinicaltrials.gov, NCT02118792.

Funding: Anacor Pharmaceuticals, Inc., a wholly owned subsidiary of Pfizer Inc., New York, NY.

Keywords: Atopic dermatitis; Crisaborole; Eczema; PDE4; Phosphodiesterase 4; Quality of life; Topical treatment

\section{INTRODUCTION}

Atopic dermatitis (AD), a chronic inflammatory skin disorder [1-3], affects an estimated 15-30\% of children and $2-10 \%$ of adults worldwide $[1,4]$. The clinical symptoms and visible skin lesions of $\mathrm{AD}$ are often associated with psychologic and psychosocial comorbidities and negatively impact the quality of life (QoL) of patients and their families [2, 4-7]. In addition, the hallmark symptom of $\mathrm{AD}$-pruritus-contributes to sleep dysfunction and reduced QoL $[2,8]$.

Treatment of $\mathrm{AD}$ with topical calcineurin inhibitors (TCIs) or topical corticosteroids (TCSs), recommended by the current treatment guidelines $[9,10]$, reduces disease severity and is associated with improved QoL for patients and their caregivers [11-13]. However, the potential impact of TCS treatment on patient QoL is often not realized because of well-documented "steroid phobia" in the majority of caregivers, leading to underdosing, decreased patient and caregiver adherence, and reduced QoL [14].

Crisaborole ointment is a nonsteroidal phosphodiesterase 4 (PDE4) inhibitor for the treatment of mild to moderate AD [15-20]. Previously published results from two large, vehicle-controlled, identically designed, phase 3 clinical studies in patients $\geq 2$ years of age with mild to moderate AD showed that significantly more crisaborole-treated patients achieved global disease severity assessments of "clear" or "almost clear", improvement in all assessed symptoms of $\mathrm{AD}$, and lessening of pruritus severity by the end of treatment [20]. These improvements in global disease severity, symptoms of $\mathrm{AD}$, and severity of pruritus can improve the QoL of patients and their families [6]. To better understand how these improvements in clinical endpoints in the two phase 3 clinical studies translate to improvements in the QoL of patients and their families, the impact of crisaborole ointment on QoL of patients $\geq 2$ years old and the parents/caregivers/families of patients 2-17 years old in these two studies was assessed.

\section{METHODS}

\section{Study Design and Treatment}

Two multicenter, randomized, double-blind, vehicle-controlled, phase 3 studies (http://www. clinicaltrials.gov; AD-301: NCT02118766; AD302: NCT02118792) were conducted to assess the efficacy and safety of crisaborole in patients $\geq 2$ years old with mild to moderate $\mathrm{AD}$; the efficacy and safety results from these studies have been published [20]. Patients were randomly assigned 2:1 to receive crisaborole ointment, 2\% (Pfizer Inc., New York, NY), or vehicle, applied twice daily for 28 days (Fig. 1). Both studies were developed and conducted in accordance with the principles of Good Clinical Practice and relevant country-specific regulatory requirements, and the protocols were approved by an institutional review board at each site. All procedures followed were in 


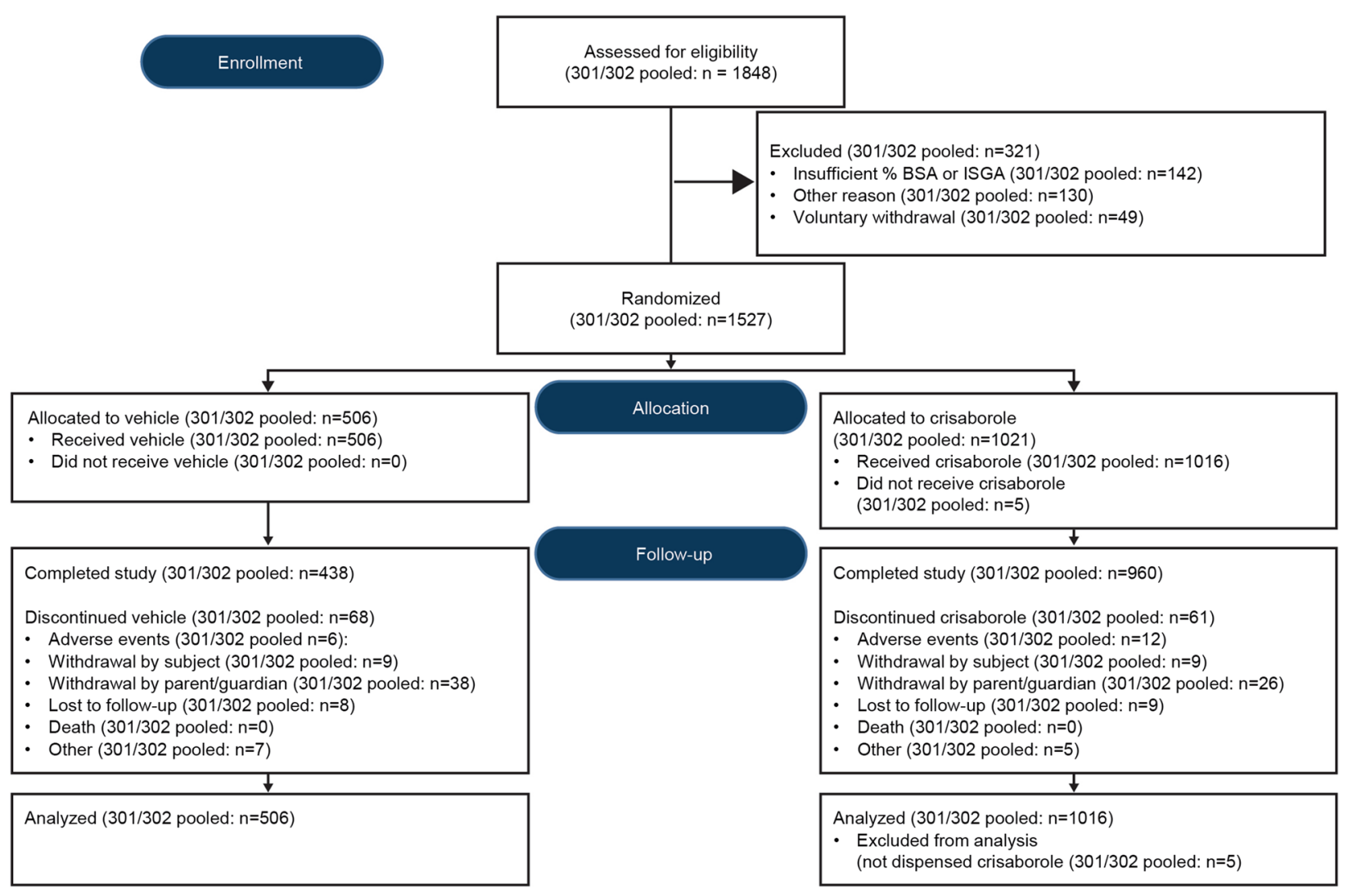

Fig. 1 CONSORT flow diagram. Enrollment, randomization, treatment, and follow-up

accordance with the ethical standards of the responsible committee on human experimentation (institutional and national) and with the Helsinki Declaration of 1964, as revised in 2013. Informed consent was obtained from all patients for being included in the study.

\section{Patients}

At baseline/day 1, patients had to be $\geq 2$ years old with a clinical diagnosis of $\mathrm{AD}$ per the Hanifin and Rajka criteria [21], have $\geq 5 \%$ treatable body surface area (BSA) involvement, and have an Investigator's Static Global Assessment (ISGA) score of mild (2) or moderate (3), assessed on a 5-point scale from clear (0) to severe (4). Key exclusion criteria were unstable $\mathrm{AD}$, the consistent need for TCSs, history of anaphylaxis or angioedema, history of biologic therapy, history of recent use of systemic or topical therapies, involvement in another drug or device research study in the preceding 30 days, or known sensitivity to any crisaborole component. The enrolled patient population reflected the overall population with $\mathrm{AD}$, with at least $20 \%$ of patients between the ages of 2 and 6 years and no more than 15\% adults.

\section{QoL Assessments}

Validated QoL scales for inflammatory skin diseases were used for assessments at baseline/day 1 and day 29 and were based on patient age at baseline/day 1 (Fig. 2). Patients $2-15$ years of age were assessed using the Children's Dermatology Life Quality Index (CDLQI) [22], and patients aged $\geq 16$ years were assessed using the Dermatology Life Quality Index (DLQI) [23]. Because the CDLQI is only validated for use in patients as young as 4 years old [22], change in CDLQI score was also assessed in the group of patients aged 4-15 years. The validated 


\begin{tabular}{|c|c|c|c|}
\hline Category & Assessment & $\begin{array}{c}\text { CDLQI } \\
\text { Patients Aged } \\
\text { 2-15 years }\end{array}$ & $\begin{array}{c}\text { DLQI } \\
\text { Patients Aged } \\
\geq 16 \text { years }\end{array}$ \\
\hline \multirow{2}{*}{$\begin{array}{l}\text { Symptoms \& } \\
\text { Feelings }\end{array}$} & Severity of symptoms (itch, soreness, pain, stinging) & $0-3 \mathrm{pts}$ & $0-3 \mathrm{pts}$ \\
\hline & Embarassment or self-conciousness & $0-3$ pts & $0-3$ pts \\
\hline \multirow{2}{*}{$\begin{array}{l}\text { Personal } \\
\text { Relationships }\end{array}$} & $\begin{array}{l}\text { Effect on friendships and social interactions } \\
\text { (eg, teasing, bulling, avoidance) }\end{array}$ & $0-6 \mathrm{pts}$ & N/A \\
\hline & Effects on friendships, relatives, and/or partner, and sex life & N/A & $0-6 \mathrm{pts}$ \\
\hline $\begin{array}{l}\text { School/Work \& } \\
\text { Holidays }\end{array}$ & Effect of skin on work/school or vacation time & $0-3$ pts & $0-3 \mathrm{pts}$ \\
\hline \multirow{2}{*}{ Leisure } & Effect on playing sports and leisure activities & $0-6$ pts & $0-6 \mathrm{pts}$ \\
\hline & Wearing different clothes/shoes & $0-3$ pts & N/A \\
\hline $\begin{array}{l}\text { Burden of } \\
\text { Treatment }\end{array}$ & Treatment burden on daily life & $0-3 \mathrm{pts}$ & $0-3$ pts \\
\hline Sleep & Effect of skin on sleep & $0-3 \mathrm{pts}$ & N/A \\
\hline Daily Activities & Influence on clothes worn and daily tasks & N/A & $0-6 \mathrm{pts}$ \\
\hline Total & Comprehensive assessment of patient QoL & $0-30 p^{0} s^{a}$ & $0-30 \mathrm{pts}^{\mathrm{a}}$ \\
\hline
\end{tabular}

B

\begin{tabular}{|l|l|}
\hline \multicolumn{2}{|l|}{ DFIa Family/Parents/Caregivers of Patients Aged 2-17 Years } \\
\hline $\begin{array}{l}\text { Questions } \\
\text { (0-3 points each) }\end{array}$ & \\
\hline Housework & Effect on housework (eg, washing, cleaning) \\
\hline Food Preparation & Impact on food preparation and feeding \\
\hline Sleep & Sleep impact on other family members \\
\hline Family Leisure & Effect on family leisure activities \\
\hline Shopping & Effect on time spent shopping for the family \\
\hline Expenditure & Increased expenditures (eg, treatment costs, clothes) \\
\hline Tiredness & Exhaustion and tiredness of parents/caregivers \\
\hline Emotional Distress & Effect on patient/caregiver emotional state (eg, depression, frustration, guilt) \\
\hline Relationships & Relationship between caregivers/partners and relationships with other children \\
\hline Burden of Treatment & Burden of child's treatment on caregiver's life \\
\hline Total (0-30 points) & Comprehensive assessment of patient QoL \\
\hline
\end{tabular}

Fig. 2 Validated QoL assessment scales and subscales. Superscript letter a indicates that subscale analysis for DFI has not been validated

Dermatitis Family Impact (DFI) scale was used to assess the effect of $\mathrm{AD}$ on the QoL of parents/caregivers/families of patients 2-17 years of age [24]. The CDLQI was originally validated for children aged 4 years and older; therefore, children younger than 4 years were aided by parental report. Each scale was descriptively summarized by treatment group, and change from baseline/day 1 results were reported. 


\section{Minimal Clinically Important Difference}

The minimal clinically important difference (MCID) is considered the smallest amount of change in the assessment instrument score that patients perceive as beneficial and that would result in a change in patient treatment in the absence of troublesome side effects and excessive cost [25]. The MCID for the CDLQI used in this analysis was $\mathrm{a} \geq 2.5$-point change from baseline [26]. For the DLQI, a longitudinal study in patients with inflammatory skin diseases demonstrated an MCID of $\geq 3$.3-point change from baseline [27]. Additional studies are necessary to validate the observed MCID for the CDLQI and DLQI in patients with AD. The MCID for the DFI questionnaire has not been established [24].

\section{CDLQI and DLQI Severity Bands}

Severity bands provide clinical interpretation of individual CDLQI and DLQI scores [28]. The effect on the child's life associated with CDLQI scores was defined as $0-1=$ "no effect," 2$6=$ "small effect," 7-12 = "moderate effect," $13-18=$ "very large effect," and 19-30 = "extremely large effect" [28]. Severity bands for patients $\geq 16$ years of age for DLQI scores were defined as $0-1=$ "no effect," 2-5 = "small effect," 6-10 = "moderate effect," 11-20 = "very large effect," and 21-30 = "extremely large effect" [29].

\section{Statistics}

Analysis of QoL measurements was performed using descriptive statistics. Differences between treatment groups in absolute change from baseline were analyzed by Wilcoxon rank sum test, a nonparametric test. Differences between treatment groups regarding the percentage of patients who experienced MCID for the CDLQI and DLQI at day 29 were analyzed using the Fisher exact test. A Wilcoxon rank sum test was used to analyze differences between treatment groups in severity bands.

\section{RESULTS}

\section{Patient Disposition and Characteristics}

Studies AD-301 and AD-302 enrolled 1016 patients treated with crisaborole and 506 patients treated with vehicle, with the first patient enrolling in March 2014 and the last visit occurring in April 2015. No significant differences were observed in baseline demographics and disease characteristics across treatment groups (Table 1). The enrolled patient population reflected the overall AD population, with $85 \%$ of patients experiencing symptoms before 5 years of age [3]. Most of the enrolled patient population was 2-15 years old (crisaborole: $80.2 \%$; vehicle: $81.4 \%$ ), and approximately one-fifth of the enrolled population was $\geq 16$ years of age (crisaborole: $19.8 \%$; vehicle: $18.6 \%)$. The severity of pruritus and QoL assessment were similar across treatment groups at baseline.

\section{Overall QoL Assessment and MCID at Day 29}

Overall, children in both the vehicle and the crisaborole groups experienced improvement in QoL during the study. Children and adolescents aged 2-15 years in the crisaborole ointment group showed greater mean reduction in QoL assessment at day 29 than patients given vehicle, as assessed by CDLQI (mean change from baseline, crisaborole: - 4.6; vehicle: - 3.0; $P<0.001$ ) (Fig. 3a). Among the subgroup of patients aged $4-15$ years, results were numerically similar and retained statistical significance (mean change from baseline, crisaborole: -4.5 ; vehicle: $-2.6 ; P<0.001$ ) (Fig. 3b). More crisaborole-treated patients (61.7\%) achieved MCID, defined as a $\geq 2.5$-point change from baseline for CDLQI [26], than vehicle-treated patients $(52.1 \%)(P=0.003)$.

Patients $\geq 16$ years of age treated with crisaborole ointment showed greater mean reduction in DLQI scores at day 29 than patients given vehicle (mean change from baseline, crisaborole: -5.2 ; vehicle: $-3.5 ; P=0.015$ ) (Fig. 3c). MCID, defined as $a \geq 3.3$-point change 
Table 1 Baseline patient characteristics and disease characteristics by age group in crisaborole phase 3 studies (ITT population)

\begin{tabular}{|c|c|c|c|c|}
\hline \multirow{2}{*}{$\begin{array}{l}\text { Patient demographics and } \\
\text { characteristics }\end{array}$} & \multicolumn{2}{|c|}{ Ages 2-15 years } & \multicolumn{2}{|c|}{ Ages $\geq 16$ years } \\
\hline & $\begin{array}{l}\text { Vehicle } \\
(n=412)\end{array}$ & $\begin{array}{l}\text { Crisaborole ointment } \\
(n=815)\end{array}$ & $\begin{array}{l}\text { Vehicle } \\
(n=94)\end{array}$ & $\begin{array}{l}\text { Crisaborole ointment } \\
(n=201)\end{array}$ \\
\hline \multicolumn{5}{|l|}{ Sex, \% } \\
\hline Male & 47.6 & 46.9 & 30.9 & 33.8 \\
\hline Female & 52.4 & 53.1 & 69.1 & 66.2 \\
\hline \multicolumn{5}{|l|}{ Ethnicity, \% } \\
\hline Hispanic or Latino & 21.4 & 20.9 & 13.8 & 14.9 \\
\hline Not Hispanic or Latino & 78.6 & 79.1 & 86.2 & 85.1 \\
\hline \multicolumn{5}{|l|}{ Race, \% } \\
\hline $\begin{array}{l}\text { American Indian or Alaskan } \\
\text { Native }\end{array}$ & 0.7 & 1.0 & 2.1 & 1.5 \\
\hline Asian & 4.4 & 4.8 & 9.6 & 6.5 \\
\hline Black or African American & 26.2 & 27.4 & 33.0 & 30.8 \\
\hline $\begin{array}{l}\text { Hawaiian or other Pacific } \\
\text { Islander }\end{array}$ & 1.7 & 0.7 & 1.1 & 0.5 \\
\hline White & 61.9 & 61.7 & 54.3 & 56.7 \\
\hline Other & 5.1 & 4.4 & 0.0 & 4.0 \\
\hline \multicolumn{5}{|l|}{ Severity of pruritus scale, $n(\%)$} \\
\hline 0 -none & $14(3.9)$ & $31(4.3)$ & $5(6.0)$ & $4(2.3)$ \\
\hline 1 -mild & $102(28.5)$ & $185(25.4)$ & $17(20.5)$ & $44(25.0)$ \\
\hline 2-moderate & $137(38.3)$ & $253(34.8)$ & $30(36.1)$ & $78(44.3)$ \\
\hline 3 -severe & $105(29.3)$ & $258(35.5)$ & $31(37.3)$ & $50(28.4)$ \\
\hline \multicolumn{5}{|l|}{ CDLQI } \\
\hline$n$ & 403 & 797 & - & - \\
\hline Mean (SD) & $9.0(6.02)$ & $9.3(5.99)$ & - & - \\
\hline \multicolumn{5}{|l|}{ DLQI } \\
\hline$n$ & - & - & 92 & 192 \\
\hline Mean $(S D)$ & - & - & $9.3(6.55)$ & $9.7(6.29)$ \\
\hline \multicolumn{5}{|c|}{ DFI (parents/caregivers/families of patients ages 2-17 years) } \\
\hline$n$ & 431 & 862 & - & - \\
\hline Mean (SD) & $7.8(6.17)$ & $8.1(6.61)$ & - & - \\
\hline
\end{tabular}

CDLQI Children's Dermatology Life Quality Index, DLQI Dermatology Life Quality Index, DFI Dermatitis Family Impact Questionnaire, ITT intent-to-treat, $S D$ standard deviation 

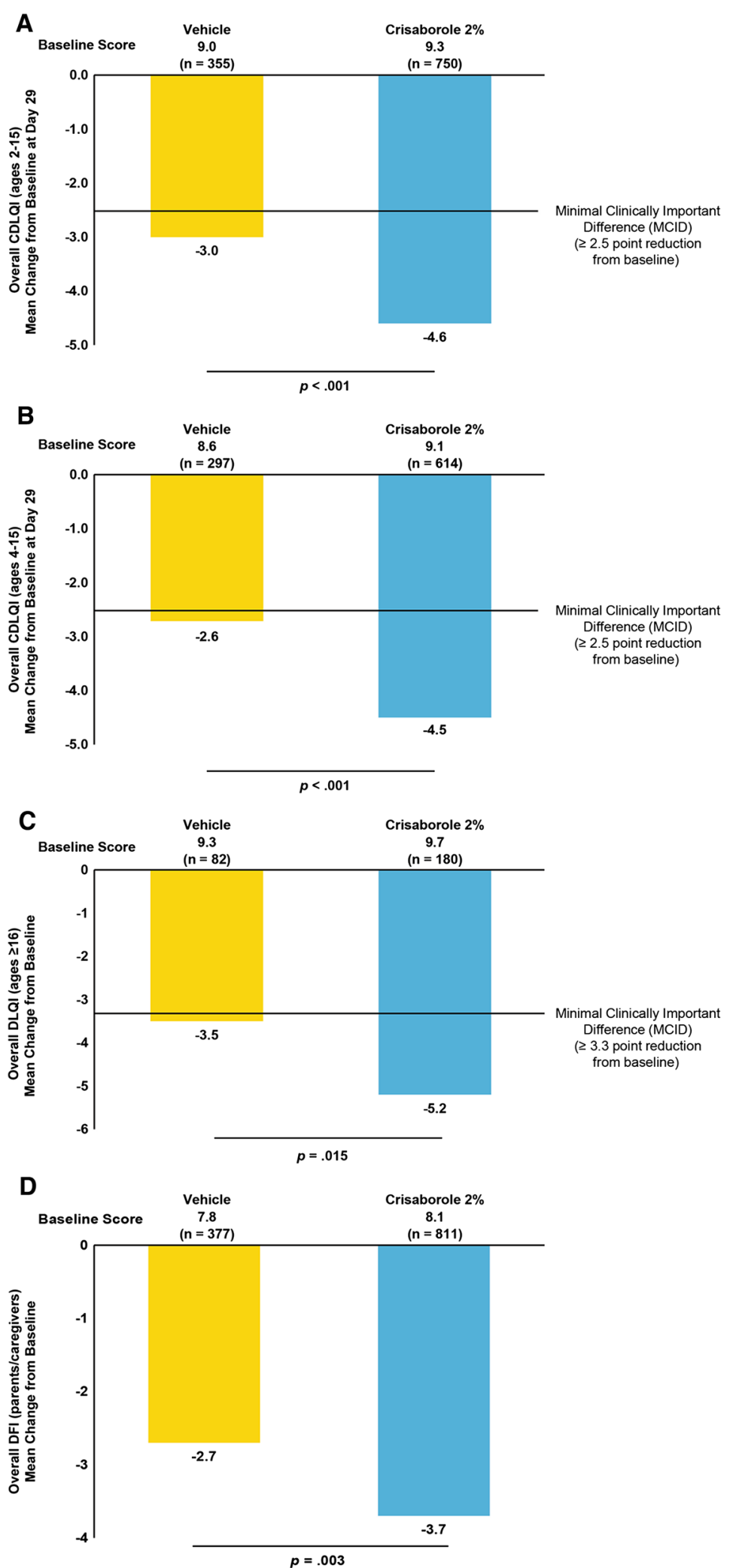

Fig. 3 Mean change from baseline in a CDLQI ages 2-15 years, b CDLQI ages 4-15 years, c DLQI, and d DFI scores (pooled analysis, ITT population) 
from baseline [27], was achieved by $53.9 \%$ of crisaborole-treated patients and $41.5 \%$ of vehicle-treated patients $(P=0.083)$. Assessment of improvement in QoL for the parents, caregivers, and families of children and adolescents with AD showed that crisaborole-treated patients showed greater mean reduction overall (mean change from baseline, crisaborole: -3.7 ; vehicle: $-2.7 ; P=0.003$ ) (Fig. $3 \mathrm{~d}$ ).

\section{Severity Bands for CDLQI and DLQI}

To provide clinical context to CDLQI and DLQI scores, established severity bands ranging from "no effect" to an "extremely large effect" were analyzed. Most children and adolescents experienced a "moderate effect" of $\mathrm{AD}$ on QoL at baseline (crisaborole: $35.3 \%$; vehicle: $34.0 \%$ ) or worse (crisaborole: 27.2\%; vehicle: 24.6\%; $P=0.1769$ ) (Fig. 4a). By day 29, crisaborole

\section{A}

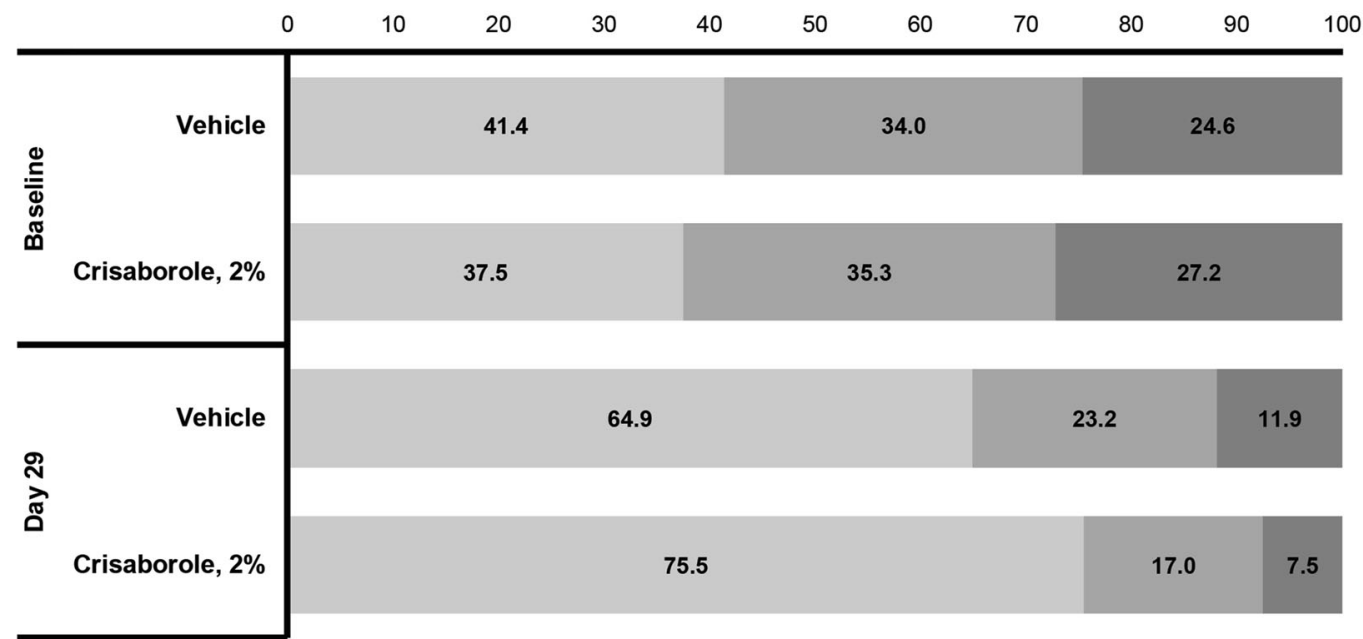

No Effect (0-1) \& Small Effect (2-6) $\quad$ Moderate Effect (7-12) =Very Large Effect (13-18) \& Extremely Large Effect (19-30)

B

Severity Bands for DLQI, \% of patients

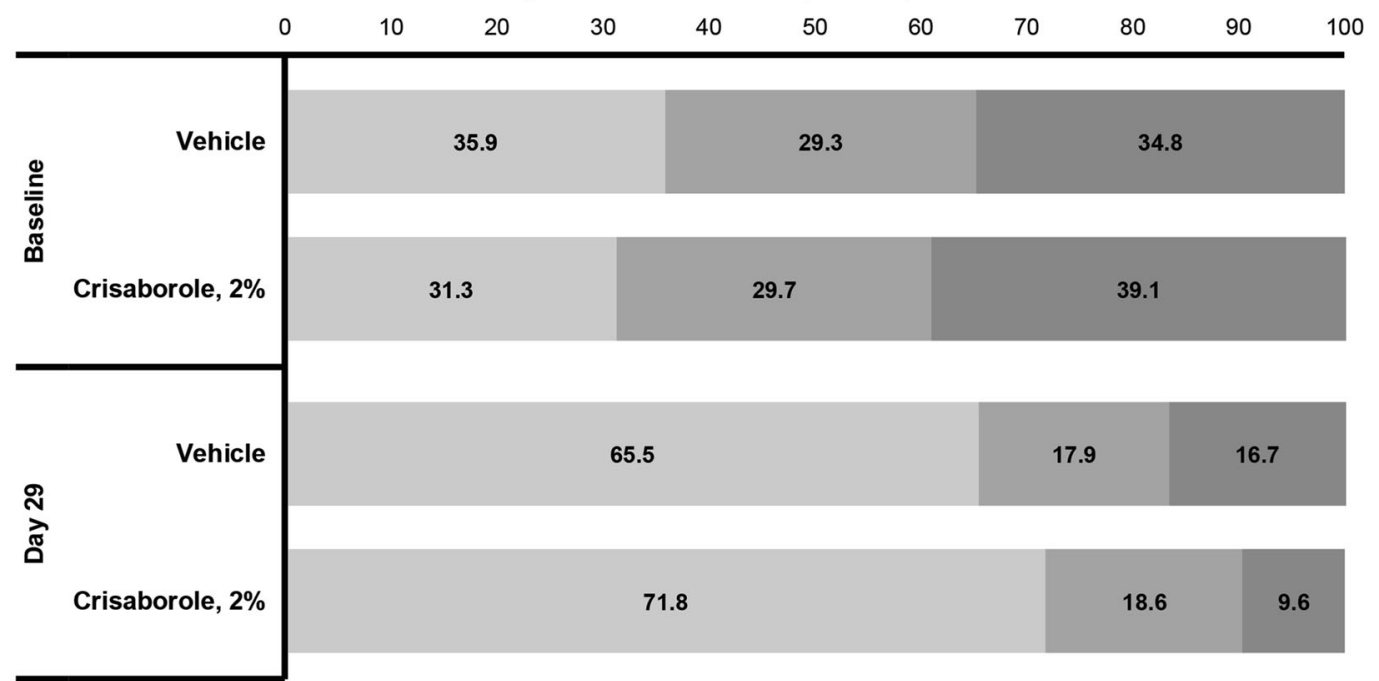

$\varpi$ No Effect (0-1) \& Small Effect (2-5) $\quad$ Moderate Effect (6-10) $\quad$ Very Large Effect (11-20) \& Extremely Large Effect (21-30)

Fig. 4 Severity bands for a CDLQI and $\mathbf{b}$ DLQI overall (pooled analysis, ITT population) 
Table 2 Responses per question for CDLQI (ITT population)

\begin{tabular}{|c|c|c|c|c|c|c|}
\hline \multirow[t]{2}{*}{ Question } & \multirow[t]{2}{*}{ Treatment } & \multicolumn{4}{|c|}{ Patients per response, \% } & \multirow[t]{2}{*}{$P$ value ${ }^{\mathrm{a}, \mathrm{b}}$} \\
\hline & & Not at all & Only a little & Quite a lot & Very much & \\
\hline \multirow[t]{2}{*}{ Itching/scratching, painful/sore } & Vebicle & 13.5 & 48.9 & 24.9 & 12.7 & $<0.001$ \\
\hline & Crisaborole ointment & 18.6 & 57.9 & 17.1 & 6.4 & \\
\hline \multirow[t]{2}{*}{ Embarrassed/self-conscious } & Vehicle & 61.0 & 23.8 & 10.5 & 4.7 & 0.011 \\
\hline & Crisaborole ointment & 68.2 & 21.2 & 7.7 & 2.9 & \\
\hline \multirow[t]{2}{*}{ Affected friendships } & Vehicle & 90.1 & 6.1 & 2.2 & 1.7 & 0.241 \\
\hline & Crisaborole ointment & 92.0 & 6.6 & 0.8 & 0.7 & \\
\hline \multirow[t]{2}{*}{ Affected clothing } & Vehicle & 61.3 & 24.6 & 8.8 & 5.2 & 0.210 \\
\hline & Crisaborole ointment & 64.2 & 25.6 & 6.7 & 3.6 & \\
\hline \multirow[t]{2}{*}{ Playing } & Vehicle & 62.4 & 26.8 & 6.6 & 4.1 & 0.010 \\
\hline & Crisaborole ointment & 69.5 & 23.8 & 4.5 & 2.2 & \\
\hline \multirow[t]{2}{*}{ Sports } & Vehicle & 74.0 & 16.0 & 5.2 & 4.7 & 0.205 \\
\hline & Crisaborole ointment & 77.6 & 13.9 & 3.8 & 4.7 & \\
\hline \multirow[t]{2}{*}{ School time } & Vehicle & 75.0 & 15.9 & 6.9 & 2.2 & 0.155 \\
\hline & Crisaborole ointment & 79.1 & 16.1 & 3.1 & 1.7 & \\
\hline \multirow[t]{2}{*}{ Holiday time } & Vebicle & 61.2 & 25.9 & 5.8 & 7.2 & 0.039 \\
\hline & Crisaborole ointment & 69.9 & 22.7 & 6.0 & 1.3 & \\
\hline \multirow[t]{2}{*}{ Teasing/bullying } & Vehicle & 82.8 & 11.9 & 3.6 & 1.7 & 0.210 \\
\hline & Crisaborole ointment & 85.5 & 11.2 & 1.8 & 1.4 & \\
\hline \multirow[t]{2}{*}{ Child sleep } & Vebicle & 42.3 & 34.5 & 13.5 & 9.7 & 0.001 \\
\hline & Crisaborole ointment & 51.4 & 33.0 & 9.3 & 6.2 & \\
\hline \multirow[t]{2}{*}{ Burden of treatment } & Vehicle & 49.7 & 34.5 & 11.0 & 4.7 & 0.001 \\
\hline & Crisaborole ointment & 60.2 & 29.2 & 7.4 & 3.3 & \\
\hline
\end{tabular}

CDLQI Children's Dermatology Life Quality Index, ITT intent-to-treat

a $P$ value from a Wilcoxon rank sum test with factor of treatment group

b Italic rows indicate statistically significant difference in question response between crisaborole and vehicle treatment groups

treatment led to an improvement in QoL, with $75.5 \%$ of patients reporting that their $\mathrm{AD}$ had "small effect" to "no effect," compared with $64.9 \%$ of vehicle-treated patients $(P=0.0002)$. For patients $\geq 16$ years of age, most reported that $\mathrm{AD}$ had a "moderate effect" on QoL at baseline (crisaborole: $29.7 \%$; vehicle: $29.3 \%$ ) or worse (crisaborole: $39.1 \%$; vehicle: $34.8 \%$;
$P=0.4030$ ) (Fig. 4b). By day 29, a numerically greater proportion of crisaborole-treated patients reported that AD had "small effect" to "no effect" (71.8\%) than vehicle-treated patients $(65.5 \% ; P=0.1400)$. These data indicate an overall reduction in the impact of AD on the lives of patients, especially for those who received crisaborole ointment. 


\section{CDLQI, DLQI, and DFI: Question Level Analysis}

Compared with vehicle-treated patients, more children and adolescents treated with crisaborole ointment experienced less impact on QoL related to itching/scratching and painful/sore $(P<0.001)$, feelings of embarrassment and selfconsciousness $(P=0.011)$, playing $(P=0.010)$, holiday time $(P=0.039)$, sleep $(P=0.001)$, and the burden of treatment $(P=0.001)$ (Table 2$)$. Similarly, more crisaborole-treated patients than vehicle-treated patients $\geq 16$ years of age reported less impact on QoL for itching/ scratching and painful/sore $(P=0.001)$, embarrassment and self-consciousness $(P=0.024)$, and sexual difficulties between partners $(P=0.017) \quad$ (Table 3$)$. The parents/caregivers/families of patients $2-17$ years of age treated with crisaborole experienced greater

Table 3 Responses per question for DLQI (ITT population)

\begin{tabular}{|c|c|c|c|c|c|c|}
\hline \multirow[t]{2}{*}{ Question } & \multirow[t]{2}{*}{ Treatment } & \multicolumn{4}{|c|}{ Patients per response, \% } & \multirow[t]{2}{*}{$P$ value ${ }^{\mathrm{a}, \mathrm{b}}$} \\
\hline & & Not at all & Only a little & Quite a lot & $\overline{\text { Very much }}$ & \\
\hline \multirow[t]{2}{*}{ Itching/scratching, painful/sore } & Vebicle & 8.3 & 65.5 & 16.7 & 9.5 & \multirow[t]{2}{*}{0.001} \\
\hline & Crisaborole ointment & 27.1 & 56.4 & 12.2 & 4.3 & \\
\hline \multirow[t]{2}{*}{ Embarrassed/self-conscious } & Vebicle & 47.6 & 25.0 & 11.9 & 15.5 & \multirow[t]{2}{*}{0.024} \\
\hline & Crisaborole ointment & 56.9 & 31.4 & 6.9 & 4.8 & \\
\hline \multirow[t]{2}{*}{ Shopping, home, yard activities } & Vehicle & 81.0 & 13.1 & 2.4 & 3.6 & \multirow[t]{2}{*}{0.391} \\
\hline & Crisaborole ointment & 75.5 & 19.7 & 3.7 & 1.1 & \\
\hline \multirow[t]{2}{*}{ Influenced clothes worn } & Vehicle & 47.6 & 25.0 & 9.5 & 17.9 & \multirow[t]{2}{*}{0.063} \\
\hline & Crisaborole ointment & 55.9 & 27.1 & 11.2 & 5.9 & \\
\hline \multirow[t]{2}{*}{ Affected social/leisure activity } & Vehicle & 70.2 & 17.9 & 6.0 & 6.0 & \multirow[t]{2}{*}{0.366} \\
\hline & Crisaborole ointment & 73.9 & 20.7 & 3.7 & 1.6 & \\
\hline \multirow[t]{2}{*}{ Affected sports participation } & Vehicle & 79.8 & 16.7 & 0.0 & 3.6 & \multirow[t]{2}{*}{0.556} \\
\hline & Crisaborole ointment & 83.0 & 12.2 & 3.7 & 1.1 & \\
\hline \multirow[t]{2}{*}{ Affected work/studying } & Vehicle & 70.2 & 23.8 & 3.6 & 2.4 & \multirow[t]{2}{*}{0.193} \\
\hline & Crisaborole ointment & 78.7 & 13.8 & 1.6 & 5.9 & \\
\hline \multirow[t]{2}{*}{ Affected relationships } & Vehicle & 75.0 & 21.4 & 1.2 & 2.4 & \multirow[t]{2}{*}{0.263} \\
\hline & Crisaborole ointment & 80.9 & 17.0 & 1.1 & 1.1 & \\
\hline \multirow[t]{2}{*}{ Sexual difficulties } & Vebicle & 86.9 & 10.7 & 0.0 & 2.4 & \multirow[t]{2}{*}{0.017} \\
\hline & Crisaborole ointment & 95.2 & 3.2 & 0.5 & 1.1 & \\
\hline \multirow[t]{2}{*}{ Burden of treatment } & Vehicle & 67.9 & 27.4 & 2.4 & 2.4 & \multirow[t]{2}{*}{0.164} \\
\hline & Crisaborole ointment & 59.6 & 31.4 & 9.0 & 0.0 & \\
\hline
\end{tabular}

DLQI Dermatology Life Quality Index, ITT intent-to-treat

a $P$ value from a Wilcoxon rank sum test with factor of treatment group

b Italic rows indicate statistically significant difference in question response between crisaborole and vehicle treatment groups 
Table 4 Responses per question for DFI (ITT population)

\begin{tabular}{|c|c|c|c|c|c|c|}
\hline \multirow[t]{2}{*}{ Question } & \multirow[t]{2}{*}{ Treatment } & \multicolumn{4}{|c|}{ Patients per response, \% } & \multirow[t]{2}{*}{$P$ value ${ }^{\mathrm{a}, \mathrm{b}}$} \\
\hline & & Not at all & Only a little & Quite a lot & Very much & \\
\hline \multirow[t]{2}{*}{ Housework } & Vehicle & 61.5 & 29.6 & 6.0 & 2.9 & 0.555 \\
\hline & Crisaborole ointment & 63.6 & 27.4 & 5.7 & 3.3 & \\
\hline \multirow[t]{2}{*}{ Food } & Vehicle & 73.8 & 18.8 & 4.7 & 2.6 & 0.142 \\
\hline & Crisaborole ointment & 77.5 & 17.2 & 3.5 & 1.8 & \\
\hline \multirow[t]{2}{*}{ Sleep } & Vebicle & 56.8 & 27.6 & 8.4 & 7.1 & 0.015 \\
\hline & Crisaborole ointment & 64.2 & 22.8 & 8.5 & 4.5 & \\
\hline \multirow[t]{2}{*}{ Leisure } & Vehicle & 66.2 & 23.8 & 5.8 & 4.2 & 0.281 \\
\hline & Crisaborole ointment & 68.7 & 24.2 & 3.8 & 3.3 & \\
\hline \multirow[t]{2}{*}{ Time shopping } & Vehicle & 78.3 & 18.6 & 1.8 & 1.3 & 0.026 \\
\hline & Crisaborole ointment & 83.7 & 13.7 & 1.6 & 1.1 & \\
\hline \multirow[t]{2}{*}{ Expenditure } & Vehicle & 63.4 & 29.3 & 5.0 & 2.4 & 0.042 \\
\hline & Crisaborole ointment & 69.9 & 23.4 & 5.0 & 2.0 & \\
\hline \multirow[t]{2}{*}{ Tiredness } & Vebicle & 60.2 & 27.7 & 7.3 & 4.7 & 0.019 \\
\hline & Crisaborole ointment & 67.2 & 22.9 & 6.2 & 3.7 & \\
\hline \multirow[t]{2}{*}{ Emotional distress } & Vehicle & 58.6 & 29.8 & 8.9 & 2.6 & 0.191 \\
\hline & Crisaborole ointment & 63.1 & 25.9 & 7.3 & 3.7 & \\
\hline \multirow[t]{2}{*}{ Relationships } & Vehicle & 76.7 & 17.8 & 4.5 & 1.0 & 0.117 \\
\hline & Crisaborole ointment & 80.8 & 14.4 & 3.3 & 1.6 & \\
\hline \multirow[t]{2}{*}{ Burden of treatment } & Vehicle & 46.5 & 36.0 & 13.4 & 4.2 & 0.201 \\
\hline & Crisaborole ointment & 49.0 & 37.8 & 9.0 & 4.3 & \\
\hline
\end{tabular}

DFI Dermatitis Family Impact Questionnaire, ITT intent-to-treat

a $P$ value from a Wilcoxon rank sum test with factor of treatment group

b Italic rows indicate statistically significant difference in question response between crisaborole and vehicle treatment groups

improvement than those of vehicle-treated patients in the categories of sleep $(P=0.015)$, time shopping $(P=0.026)$, and expenditure $(P=0.042)$ (Table 4).

\section{DISCUSSION}

The current study revealed that even mild $\mathrm{AD}$ can significantly affect patients and their families [30]; therefore, regardless of severity of AD, treatment can improve QoL for patients and their families. Crisaborole-treated patients showed greater reduction in pruritus severity than vehicle-treated patients [20] and a reduction in the impact of itching and scratching on QoL for children, adolescents, and adults. ADassociated pruritus greatly affects patient and caregiver QoL and results in sleep disruption $[2,8]$. Sleep disruption strongly affects the QoL of children and adults [31], and it is linked to the development of the mental health 
comorbidities often seen in patients with $\mathrm{AD}$ [32]. Although additional studies are necessary to fully assess the impact of crisaborole on sleep quality, crisaborole-treated children and adolescents and their families experienced lessening of the impact of $\mathrm{AD}$ on sleep.

The visibility and stigma associated with skin diseases also impacts the QoL of patients [2]. The reduction in feelings of embarrassment and self-consciousness for crisaborole-treated patients most likely results from reduction in global disease severity and diminution of lesions in visible areas [20]. Treatment of AD itself imposes a significant burden on the QoL of patients because treatment regimens are often time consuming and associated with lifestyle changes $[2,11,33,34]$. Greater disease severity is directly correlated with more time spent on treatment [34]. A greater proportion of crisaborole-treated children and adolescents experienced lessening of the burden of treatment, which might have resulted from reduction in pruritus severity and global disease severity [20]. AD also has a significant impact on the QoL of parents/caregivers/families of patients with $\mathrm{AD}$ because parents spend several hours each day dealing with treatment and lose $1-2 \mathrm{~h}$ of sleep on average each night $[2,30]$. The lessening of the impact of $\mathrm{AD}$ on sleep reported by the parents/caregivers/families of crisaborole-treated patients might reduce sleep lossassociated side effects, such as decreased coping skills and poor work functioning [2].

Available treatments, such as TCSs and TCIs, improve QoL for patients and their families. A greater mean reduction in the Parents of Children With Atopic Dermatitis (PQoL-AD) score was observed for pimecrolimus-treated patients 2-17 years of age with mild to moderate AD treated with pimecrolimus for 6 weeks (leastsquares mean change, - 3.2) compared with vehicle-treated patients $(-1.63 ; P=0.023)$ [12]. The current study showed that, similar to TCS and TCI, crisaborole ointment improves QoL for patients and their caregivers. Direct comparison of TCS and TCI studies with those of crisaborole are not feasible because of the lack of head-tohead trials and differences in study design, assessment tools used, and patient populations in the individual studies. The large "vehicle effect" seen with the pimecrolimus study and in the current study is commonly observed in $\mathrm{AD}$ clinical trials. Topical vehicle is not a placebo, and emollients are the foundation of step care in management of $\mathrm{AD}$ [35]. Use of emollients reduces the need for topical steroids in children [36], and emollient therapy is a prevention strategy in high-risk neonates [37]. Petrolatum, a common moisturizer and the main component of the base for the crisaborole ointment and the vehicle ointment, has skin barrier repair and immune-modulating properties [38]. Compared with vehicle alone, the addition of crisaborole improves QoL for patients with $\mathrm{AD}$ and their parents/caregivers/families.

Potential limitations with these studies include the use of CDLQI and DLQI in AD because, although both measurement tools are validated for inflammatory skin diseases and commonly used in $\mathrm{AD}$ trials, these measures are not specific for $\mathrm{AD}$ and might not fully capture the impact of the disease $[39,40]$. In addition, the CDLQI has been validated in patients 4 years or older only [22]; therefore, younger patients were aided by a parent/caregiver. However, analysis of the subgroup aged 415 years showed a change in CDLQI similar to that seen in the cohort aged 2-15 years.

\section{CONCLUSIONS}

Despite the limitations of the study, the improvements in QoL described herein demonstrate that the reduction in objective lesion severity observed in previous analysis $[16-18,20]$ is clinically meaningful for patients and their families. Crisaborole is a promising novel topical $\mathrm{AD}$ treatment that improves mild to moderate $\mathrm{AD}$ and the lives of affected patients and their families.

\section{ACKNOWLEDGEMENTS}

The authors thank the study patients, investigators, and investigational sites, whose participation made these studies possible. 
Funding. This study was sponsored by Anacor Pharmaceuticals, Inc., a wholly owned subsidiary of Pfizer Inc., New York, NY. Pfizer Inc. funded the article processing charges. All authors had full access to all the data in this study and take complete responsibility for the integrity of the data and accuracy of the data analysis.

Medical Writing, Editorial, and Other Assistance. The authors thank the participants of these studies; Huaming Tan, Ph.D., of Pfizer Inc., for performing the statistical analyses; and Michael Zielinski, PharmD, and Anna Tallman, PharmD, of Pfizer Inc., who provided critical review and revision of the manuscript. Editorial/medical writing support under the guidance of the authors was provided by Sarah Utley, Ph.D., and Corey Mandel, Ph.D., of ApotheCom, San Francisco, CA, USA, and was funded by Anacor Pharmaceuticals, Inc., a wholly owned subsidiary of Pfizer Inc., New York, NY, USA, in accordance with Good Publication Practice (GPP3) guidelines (Ann Intern Med. 2015;163:461-464).

Authorship. All named authors meet the International Committee of Medical Journal Editors (ICMJE) criteria for authorship for this manuscript, take responsibility for the integrity of the work as a whole, and have given final approval for the version to be published.

Disclosures. Pfizer Inc. supplied grants to the institution of Dr. Paller to conduct the studies. Pfizer Inc. supplied grants to the institution of Dr. Boguniewicz to conduct the studies. Pfizer Inc. supplied grants to the institution of Dr. Feldman to conduct the studies. Dr. Simpson's institution has received funding from GlaxoSmithKline, Regeneron Pharmaceuticals, Novartis, Vanda Pharmaceuticals, and Tioga Pharmaceuticals Inc. to conduct clinical trials. Dr. Simpson received consulting fees from Galderma, Genentech Inc., GlaxoSmithKline, Regeneron, and Pfizer Inc., and received advisory board honoraria from Celgene, Dermira, Regeneron, and Sanofi. Dr. Paller has received consulting fees from Eli Lilly, Celgene, Novartis, Sanofi-Regeneron, and Valeant
Pharmaceuticals. Dr. Boguniewicz has received consulting fees from Pfizer Inc. The institution of Dr. Eichenfield received funding from Otsuka, Medimetriks Pharmaceuticals, Roivant Sciences, Sanofi-Regeneron, and Valeant Pharmaceuticals. Dr. Eichenfield has received consulting honoraria from Eli Lilly, Galderma, Pfizer Inc., Anacor Pharmaceuticals, Inc., Novartis, Roivant Sciences, and Valeant Pharmaceuticals. Dr. Feldman received consulting fees from Pfizer Inc. Dr. Silverberg received advisory board and consulting honoraria from Pfizer Inc., Anacor Pharmaceuticals, Inc., AbbVie, Eli Lilly, GlaxoSmithKline, Realm-1, SanofiRegeneron, Kiniksa, Menlo, and Galderma. The institution of Dr. Silverberg has received funding from Celgene, Eli Lilly, GlaxoSmithKline, Regeneron-Sanofi, and Realm Therapeutics for conducting clinical trials. At the time of the study, Dr. Zane was an employee and shareholder of Anacor Pharmaceuticals, Inc., which was acquired by Pfizer Inc. Dr. Chamlin has received consulting fees from Menlo Therapeutics, Valeant Pharmaceuticals, and Pierre Fabre Laboratories. All authors have contributed to writing the first draft of the manuscript and no honorarium, grant, or other form of payment was given to anyone to produce the manuscript.

Compliance with Ethics Guidelines. All procedures followed were in accordance with the ethical standards of the responsible committee on human experimentation (institutional and national) and with the Helsinki Declaration of 1964, as revised in 2013. Informed consent was obtained from all patients for being included in the study.

Data Availability. Upon request, and subject to certain criteria, conditions, and exceptions (see https://www.pfizer.com/science/ clinical-trials/trial-data-and-results for more information), Pfizer Inc. will provide access to individual de-identified participant data from Pfizer-sponsored global interventional clinical studies conducted for medicines, vaccines, and medical devices (1) for indications that have been approved in the United States and/or European Union or (2) in programs that have been terminated (i.e., development for all 
indications has been discontinued). Pfizer will also consider requests for the protocol, data dictionary, and statistical analysis plan. Data may be requested from Pfizer trials 24 months after study completion. The de-identified participant data will be made available to researchers whose proposals meet the research criteria and other conditions, and for which an exception does not apply, via a secure portal. To gain access, data requestors must enter into a data access agreement with Pfizer.

Open Access. This article is distributed under the terms of the Creative Commons Attribution-NonCommercial 4.0 International License (http://creativecommons.org/licenses/ by-nc/4.0/), which permits any noncommercial use, distribution, and reproduction in any medium, provided you give appropriate credit to the original author(s) and the source, provide a link to the Creative Commons license, and indicate if changes were made.

\section{REFERENCES}

1. Bieber T. Atopic dermatitis. $\mathrm{N}$ Engl J Med. 2008;358:1483-94.

2. Carroll CL, Balkrishnan R, Feldman SR, Fleischer AB Jr, Manuel JC. The burden of atopic dermatitis: impact on the patient, family, and society. Pediatr Dermatol. 2005;22:192-9.

3. Nutten S. Atopic dermatitis: global epidemiology and risk factors. Ann Nutr Metab. 2015;66(suppl 1):8-16.

4. Bieber T. Atopic dermatitis. Ann Dermatol. 2010;22:125-37.

5. Garg N, Silverberg JI. Association between childhood allergic disease, psychological comorbidity, and injury requiring medical attention. Ann Allergy Asthma Immunol. 2014;112:525-32.

6. Beattie PE, Lewis-Jones MS. A comparative study of impairment of quality of life in children with skin disease and children with other chronic childhood diseases. Br J Dermatol. 2006;155:145-51.

7. Halvorsen JA, Lien L, Dalgard F, Bjertness E, Stern RS. Suicidal ideation, mental health problems, and social function in adolescents with eczema: a population-based study. J Investig Dermatol. 2014; 134:1847-54.

8. Chang YS, Chou YT, Lee JH, et al. Atopic dermatitis, melatonin, and sleep disturbance. Pediatrics. 2014;134:e397-405.

9. Eichenfield LF, Tom WL, Berger TG, et al. Guidelines of care for the management of atopic dermatitis: section 2. Management and treatment of atopic dermatitis with topical therapies. J Am Acad Dermatol. 2014;71:116-32.

10. Schneider L, Tilles S, Lio P, et al. Atopic dermatitis: a practice parameter update 2012. J Allergy Clin Immunol. 2013;131:295-9.

11. Drake L, Prendergast M, Maher R, et al. The impact of tacrolimus ointment on health-related quality of life of adult and pediatric patients with atopic dermatitis. J Am Acad Dermatol. 2001;44:S65-72.

12. Whalley D, Huels J, McKenna SP, Van AD. The benefit of pimecrolimus (Elidel, SDZ ASM 981) on parents' quality of life in the treatment of pediatric atopic dermatitis. Pediatrics. 2002;110:1133-6.

13. Staab D, Kaufmann R, Brautigam M, Wahn U. Treatment of infants with atopic eczema with pimecrolimus cream 1\% improves parents' quality of life: a multicenter, randomized trial. Pediatr Allergy Immunol. 2005;16:527-33.

14. Hon KL, Tsang YC, Pong NH, et al. Correlations among steroid fear, acceptability, usage frequency, quality of life and disease severity in childhood eczema. J Dermatol Treat. 2015;26:418-25.

15. Zane LT, Chanda S, Jarnagin K, Nelson DB, Spelman L, Stein Gold LF. Crisaborole and its potential role in treating atopic dermatitis: overview of early clinical studies. Immunotherapy. 2016;8:866.

16. Stein Gold LF, Spelman L, Spellman MC, Hughes $\mathrm{MH}$, Zane LT. A phase 2, randomized, controlled, dose-ranging study evaluating crisaborole topical ointment, $0.5 \%$ and $2 \%$ in adolescents with mild to moderate atopic dermatitis. J Drugs Dermatol. 2015;14:1394-9.

17. Murrell D, Gebauer K, Spelman L, Zane LT. Crisaborole topical ointment, $2 \%$ in adults with atopic dermatitis: a phase $2 \mathrm{~A}$, vehicle-controlled, proof-ofconcept study. J Drugs Dermatol. 2015;14:1108-12.

18. Tom WL, Van SM, Chanda S, Zane LT. Pharmacokinetic profile, safety, and tolerability of crisaborole topical ointment, $2 \%$ in adolescents with atopic dermatitis: an open-label phase 2a study. Pediatr Dermatol. 2016;33:150-9. 
19. Zane LT, Kircik L, Call R, et al. Crisaborole topical ointment, $2 \%$ in patients 2 to 17 years of age with atopic dermatitis: a phase $1 \mathrm{~b}$, open-label, maximaluse systemic exposure (MUSE) study. Pediatr Dermatol. 2016;33:380-7.

20. Paller AS, Wynnis TL, Lebwohl MG, et al. Efficacy and safety of crisaborole ointment, a novel, nonsteroidal phosphodiesterase 4 (PDE4) inhibitor for the topical treatment of atopic dermatitis (AD) in children and adults. J Am Acad Dermatol. 2016;75(494-503):e6.

21. Hanifin JM, Rajka G. Diagnostic features of atopic dermatitis. Acta Derm Venereol. 1980;92:47.

22. Lewis-Jones MS, Finlay AY. The Children's Dermatology Life Quality Index (CDLQI): initial validation and practical use. $\mathrm{Br} \mathrm{J}$ Dermatol. $1995 ; 132: 942-9$.

23. Finlay AY, Khan GK. Dermatology Life Quality Index (DLQI) - a simple practical measure for routine clinical use. Clin Exp Dermatol. 1994;19:210-6.

24. Dodington SR, Basra MK, Finlay AY, Salek MS. The Dermatitis Family Impact Questionnaire: a review of its measurement properties and clinical application. Br J Dermatol. 2013;169:31-46.

25. Jaeschke R, Singer J, Guyatt GH. Measurement of health status. Ascertaining the minimal clinically important difference. Control Clin Trials. 1989;10:407-15.

26. Salek MS, Jung S, Brincat-Ruffini LA, et al. Clinical experience and psychometric properties of the Children's Dermatology Life Quality Index (CDLQI), 1995-2012. Br J Dermatol. 2013;169:734-59.

27. Basra MK, Salek MS, Camilleri L, Sturkey R, Finlay AY. Determining the minimal clinically important difference and responsiveness of the Dermatology Life Quality Index (DLQI): further data. Dermatology. 2015;230:27-33.

28. Waters A, Sandhu D, Beattie P, Lewis-Jones S. Severity stratification of Children's Dermatology Life Quality Index (CDLQI) scores. Br J Dermatol. 2010;163:121.

29. Hongbo Y, Thomas CL, Harrison MA, Salek MS, Finlay AY. Translating the science of quality of life into practice: what do Dermatology Life Quality Index scores mean? J Investig Dermatol. 2005;125:659-64.
30. Su JC, Kemp AS, Varigos GA, Nolan TM. Atopic eczema: its impact on the family and financial cost. Arch Dis Child. 1997;76:159-62.

31. Kong TS, Han TY, Lee JH, Son SJ. Correlation between severity of atopic dermatitis and sleep quality in children and adults. Ann Dermatol. 2016;28:321-6.

32. Simpson EL. Comorbidity in atopic dermatitis. Curr Dermatol Rep. 2012;1:29-38.

33. Lewis-Jones S. Quality of life and childhood atopic dermatitis: the misery of living with childhood eczema. Int J Clin Pract. 2006;60:984-92.

34. Holm EA, Jemec GB. Time spent on treatment of atopic dermatitis: a new method of measuring pediatric morbidity? Pediatr Dermatol. 2004;21:623-7.

35. Akdis CA, Akdis M, Bieber T, et al. Diagnosis and treatment of atopic dermatitis in children and adults: European Academy of Allergology and Clinical Immunology/American Academy of Allergy, Asthma and Immunology/PRACTALL Consensus Report. J Allergy Clin Immunol. 2006;118:152-69.

36. Lucky AW, Leach AD, Laskarzewski P, Wenck H. Use of an emollient as a steroid-sparing agent in the treatment of mild to moderate atopic dermatitis in children. Pediatr Dermatol. 1997;14:321-4.

37. Simpson EL, Chalmers JR, Hanifin JM, et al. Emollient enhancement of the skin barrier from birth offers effective atopic dermatitis prevention. J Allergy Clin Immunol. 2014;134:818-23.

38. Czarnowicki T, Malajian D, Khattri S, et al. Petrolatum: barrier repair and antimicrobial responses underlying this "inert" moisturizer. J Allergy Clin Immunol. 2016;137(1091-102):e7.

39. Rehal B, Armstrong AW. Health outcome measures in atopic dermatitis: a systematic review of trends in disease severity and quality-of-life instruments 1985-2010. PLoS One. 2011;6:e17520.

40. Twiss J, Meads DM, Preston EP, Crawford SR, McKenna SP. Can we rely on the Dermatology Life Quality Index as a measure of the impact of psoriasis or atopic dermatitis? J Investig Dermatol. 2012;132:76-84. 